\title{
Tratado médico-filosófico sobre a alienação mental ou a mania (1801)*
}

(extratos sobre a mania e sobre o tratamento moral)

Philippe Pinel

(p. 16 a 29)

VI - Sinais precursores dos acessos de mania

A natureza das afecções específicas que dão origem à mania periódica, e ainda as afinidades dessa doença com a melancolia e a hipocondria, levam à suposição que sua sede primitiva quase sempre está na região epigástrica, e que é a partir desse centro que se propagam, como numa espécie de irradiação, os acessos de mania. O exame cuidadoso de seus sinais precursores dão, ainda, provas bastante surpreendentes do domínio tão vasto que Lacaze e Bordeu dão a estas forças epigástricas, e que Buffon tão bem descreveu em sua história natural; é de fato toda a região abdominal que logo parece entrar nesse acordo simpático. No prelúdio dos acessos, os doentes queixam-se de um aperto na região do estômago, de uma repugnância pelos alimentos, de uma constipação severa, de ardores nas entranhas que os fazem procurar bebidas refrescantes; agitações, vagas inquietudes, terrores, pânicos, insônias. Pouco tempo depois a desordem e a perturbação de idéias são

* Pinel, P. Traité Médico-Philosophique sur l'Aliénation Mentale ou la Manie. Paris: Richard, Caille e Ravier, 1801. Tradução por Maria Vera Pompeo de Camargo Pacheco. Revisão técnica pelo Prof. Dr. Mário Eduardo Costa Pereira, ambos do Laboratório de Psicopatologia Fundamental da Unicamp. 
exteriorizadas por gestos insólitos, por singularidades na contenção e movimentos do corpo, que não podem deixar de surpreender profundamente um olhar observador. $\mathrm{O}$ alienado algumas vezes mantém a cabeça elevada e o olhar fixo no céu, ele fala em voz baixa, desloca-se e pára alternadamente, com um ar de admiração raciocinada, ou uma espécie de profundo recolhimento. Em outros alienados manifestam-se excessos inúteis de um humor jovial e gargalhadas incontroláveis. Algumas vezes, também, como se a natureza se satisfizesse com os contrastes, manifesta-se uma seriedade sombria, uma efusão de lágrimas sem causa conhecida, ou mesmo uma tristeza concentrada e angústias extremas. Em alguns casos, a vermelhidão quase súbita dos olhos, o olhar brilhante, o colorido da face, uma loquacidade exuberante, fazem pressentir a proximidade do acesso, e a necessidade urgente de uma reclusão rigorosa. Um alienado que fale de início com loquacidade, dê gargalhadas freqüentes e caia em seguida numa torrente de lágrimas; a experiência adverte para prontamente encerrá-lo, pois esses acessos são da maior violência, e ele irá transformar em pedaços tudo o que lhe cair nas mãos. Os acessos de devoção maníaca freqüentemente iniciam-se por visões de êxtases durante a noite. A mania por amor irrompe também algumas vezes com furor, após intervalos mais ou menos longos de razão e calma, por sonhos encantadores e por uma pretensa aparição do objeto amado, com traços de uma beleza radiante.

\section{VII - Mudança das afecções morais durante o acesso}

Quem olhou a cólera como furor ou mania passageira /.../, exprimiu um pensamento muito verdadeiro, cuja profundidade pode ser sentida quanto mais oportunidade se tenha tido de observar e de comparar um grande número de acessos de mania, já que em geral eles mostram-se sob forma de um arrebatamento prolongado, mais ou menos impetuoso. São muito mais essas emoções de natureza irascível que constituem a verdadeira característica desses acessos, do que a perturbação de idéias ou as singularidades bizarras do julgamento. Encontramos também a designação de mania como sinônimo de furor, nos escritos de Areteu e de Caelius Aurelianus, que foram excelentes na arte de observar. Deve-se apenas rever a extensão grande demais que deram a esse termo, já que algumas vezes observa-se acessos sem furor, mas quase nunca sem uma espécie de alteração ou de perversão das qualidades morais. Um homem, que se tornou maníaco pelos acontecimentos da revolução, no momento do acesso repeliu rudemente uma criança que ele amava ternamente em outros tempos.

Vi também um homem jovem muito ligado a seu pai, insultá-lo, ou inclusive tentar agredi-lo fisicamente durante seus acessos periódicos, e que não eram 
absolutamente acompanhados de furor. Eu poderia citar alguns exemplos de alienados, conhecidos aliás por uma honestidade rígida nos seus intervalos de calma, mas que durante seus acessos tornavam-se notáveis por uma tendência irresistível de roubar e de trapacear. Um outro insano, de natureza pacífica e muito suave, durante seus acessos parecia inspirado pelo demônio da malícia; ficava permanentemente numa atividade nociva: trancava seus companheiros nos alojamentos, provocava-os, batia neles e suscitava querelas e rixas de todas as formas.

Mas como conceber o instinto destrutivo de alguns alienados, ocupados incessantemente em rasgar e esfarrapar tudo o que podem alcançar? Algumas vezes, é sem dúvida por um erro da imaginação, como o prova o exemplo de um insano que rasgou as roupas de cama e a palha de seu colchão, que acreditava ser um amontoado de serpentes e cobras enroladas. Existe, também, entre esses furiosos, aqueles cuja imaginação não está absolutamente lesada e que sentem uma propensão cega e feroz de mergulhar suas mãos no sangue e de rasgar as entranhas de seus semelhantes. É uma confissão que eu ouvi, tremendo, da própria boca de um desses insanos, em seus intervalos de tranqüilidade. Enfim, para completar esse quadro de uma atrocidade evidente, posso citar o exemplo de um alienado que voltava seu furor ilimitado contra si e contra os outros. Ele amputou sua própria mão com um cutelo, antes de chegar em Bicêtre, e apesar de suas amarras, tentava aproximar seus dentes da coxa para devorá-la. Esse infeliz terminou por sucumbir num desses acessos de raiva maníaca e suicida.

\section{VIII - Diversas lesões das funções e da compreensão durante os acessos}

Sabe-se que Condillac, para melhor retomar - pela análise - a origem de nossos conhecimentos, supõe uma estátua animada e dotada das funções do olfato, do paladar, da audição, da visão e do tato e assim chega a indicar as idéias que devem ser relacionadas a impressões diversas. Da mesma maneira, em nada importa para a história da compreensão humana poder considerar de forma isolada suas diversas funções - como a atenção, a comparação, o julgamento, a reflexão, a imaginação, a memória e o raciocínio - com as alterações às quais estas funções são susceptíveis? Por vezes um acesso de mania oferece todas as variedades que se poderia procurar pela via da abstração. Ora essas funções são abolidas todas juntas, enfraquecidas ou vivamente excitadas durante os acessos, ora essa alteração ou perversão toca apenas uma ou várias entre elas, enquanto as outras adquirem um novo grau de desenvolvimento e de atividade e parecem excluir qualquer idéia de alienação da compreensão. Não é raro ver alguns alienados mergulhados, durante os acessos, numa idéia exclusiva que os absorve por inteiro, 
e que eles manifestam em outros momentos; permanecem imóveis e silenciosos num canto de seu alojamento, rejeitam com rudeza os serviços que querem lhes prestar, e oferecem apenas as manifestações de um estupor selvagem. Isso não é mobilizar a atenção e dirigi-la para um único objeto, com o que ainda resta de vitalidade? Em outras vezes, durante seu acesso, o insano agita-se sem parar; ele alternadamente ri, canta, chora e mostra a mais versátil mobilidade, sem que nada possa fixá-lo um só momento. Eu vi alienados, por uma série de preconceitos religiosos, recusarem de início toda comida com a mais invencível obstinação, serem em seguida fortemente abalados pelo tom imperioso e ameaçador do zelador e passarem várias horas numa espécie de luta interior entre a idéia de tornaremse culpados diante da divindade, ou exporem-se a maus tratos, cedendo finalmente ao temor determinando-se a aceitar alimentos; não é questão de comparar idéias após tê-las examinado detidamente. Outras vezes o alienado parece incapaz dessa comparação e não pode sair da esfera circunscrita de sua idéia primitiva. $\mathrm{O}$ julgamento às vezes parece inteiramente obliterado durante o acesso e o insano pronuncia apenas palavras sem ordem e sem seqüência, que supõem as idéias mais incoerentes. Outra vezes o julgamento está com todo seu vigor e sua força; o insano parece moderado e dá as respostas mais justas e mais precisas às questões dos curiosos, e se lhe é dada liberdade, ele entra no maior acesso de raiva e de furor, como o provaram os deploráveis acontecimentos das prisões em 2 de setembro do ano 2 da República. Essa espécie de mania é de fato tão comum, que eu vi, ao mesmo tempo, oito exemplos dela no hospício, e que lhe é dado o nome vulgar de loucura raciocinante (folie raisonnante). Seria supérfluo falar dos desvios da imaginação, das visões fantásticas, das transformações ideais em generais de exército, em monarcas, em divindades; ilusões que fazem a característica das afecções hipocondríacas e melancólicas, tão freqüentemente observadas e descritas sob todas as formas pelos autores. Como pode-se deixar de encontrá-las na mania, que muitas vezes é o mais alto grau da hipocondria e da melancolia? Há variedades singulares para a memória, que algumas vezes parece ser inteiramente abolida, de sorte que em seus intervalos de calma os alienados não conservam nenhuma lembrança de seus desvios e de seus atos de extravagância; mas alguns entre eles recompõem claramente todas as circunstâncias do acesso, todos os propósitos ultrajantes que mantiveram, todas as irritações nas quais se deixaram levar; eles tornam-se sombrios e taciturnos durante vários dias, vivem retirados no fundo de seus alojamentos e são dados a arrepender-se, como se fosse possível culpá-los desses desvios de um ímpeto cego e irresistível. A reflexão e o raciocínio são visivelmente lesados ou destruídos na maior parte dos acessos de mania, mas pode-se citar casos nos quais uma ou outra função do entendimento persiste com toda sua energia. Ou restabelecemse prontamente quando um objeto vem a fixar os insensatos no meio de suas divagações quiméricas. Um dia eu incitei um deles, de espírito muito culto, a 
escrever-me uma carta no mesmo momento em que ele mantinha os mais absurdos propósitos e, no entanto, essa carta que eu ainda conservo, está plena de sentido e de razão. Um ourives, que tinha a extravagância de acreditar que lhe haviam trocado a cabeça, vangloriava-se ao mesmo tempo da quimera do movimento perpétuo; ele obteve suas ferramentas e entregou-se ao trabalho com a maior obstinação. Imagina-se bem que a descoberta não aconteceu, mas disso resultaram máquinas muito engenhosas, fruto necessário das mais profundas combinações. É possível conciliar todo esse conjunto de fatos com a opinião de uma sede ou princípio único e invisível do entendimento? O que acontece então com os milhares de volumes sobre a metafísica?

\section{IX - Os acessos de mania têm como característica um novo grau de energia física e moral}

Deve-se esperar que de agora em diante a medicina filosófica fará proscrever essas expressões vagas e inexatas de imagens traçadas no cérebro, de impulsão desigual do sangue nas diferentes partes desse órgão, do movimento irregular de espíritos animais, etc., expressões que ainda encontramos nas melhores obras sobre a compreensão humana, e que não podem mais estar de acordo com a origem, as causas e a história dos acessos de mania.

A excitação nervosa que caracteriza a maioria desses acessos não se marca somente no físico por um excesso de força muscular e uma agitação contínua do insano, mas também na moral, por um sentimento profundo de superioridade de suas forças, e por uma alta convicção que nada pode resistir à sua suprema vontade. Inclusive o insano é, então, dotado de uma audácia intrépida que o leva a dar livre vazão a seus caprichos extravagantes, e no caso de repressão, a desencadear um combate ao zelador e ao pessoal de serviço, a menos que se lhe oponha força e que se reúna em grande número, ou seja, para contê-lo é preciso um aparato imponente que possa agir fortemente em sua imaginação e convencêlo de que toda resistência será em vão. Eis aí um grande segredo nos hospícios bem organizados, para prevenir os acidentes funestos em casos imprevistos, e para contribuir fortemente na cura da mania. Algumas vezes eu vi também essa excitação nervosa tornar-se extrema e incoercível. Um insano, calmo há vários meses, é acometido de repente de um acesso durante um passeio; seus olhos tornaram-se brilhantes e como que fora das órbitas; seu rosto, o alto do pescoço e o peito são tomados de um rubor púrpura; ele acredita ver o sol a quatro passos de distância, diz experimentar um fervilhamento indescritível em sua cabeça e avisa que o prendam rapidamente, porque não tem mais domínio para conter seu furor. Ele continuou, durante seu acesso, a agitar-se com violência, a acreditar 
ver o sol a seu lado, a falar com uma volubilidade extrema e de mostrar apenas desordem e confusão em suas idéias. Em outras vezes, essa reação de forças epigástricas sobre as funções da compreensão, longe de oprimi-los ou de obscurecê-los, não faz outra coisa senão aumentar sua vivacidade e sua energia, talvez porque a cultura anterior do espírito e o habitual exercício do pensamento sirvam para contrabalançá-la. O acesso parece levar a imaginação ao mais alto grau de desenvolvimento e de fecundidade, sem que ela deixe de ser regular e dirigida pelo bom gosto. Os pensamentos mais impetuosos, as aproximações mais engenhosas e as mais picantes, dão ao alienado o ar sobrenatural da inspiração e do entusiasmo. A lembrança do passado parece desenrolar-se com facilidade, e o que ele havia esquecido em seus intervalos de calma, reproduz-se então em seu espírito com as mais vivas e as mais animadas cores. Às vezes eu parava, com prazer, diante do alojamento de um homem de letras que durante seus acessos discorria sobre os acontecimentos da revolução com toda a força, a dignidade e a pureza de linguagem que se teria podido esperar de um homem o mais profundamente instruído e com o mais perfeito julgamento. Em outros tempos não era mais que um homem muito comum. Essa exaltação, quando é associada à idéia quimérica de uma potência suprema, ou de uma participação na natureza divina, leva a alegria do insano aos mais extáticos prazeres e até a uma espécie de encantamento e de embriaguez de felicidade. Um insano trancado numa instituição de Paris, e que durante seus acessos acreditava ser o profeta Maomé, tomava então a atitude de comando e o tom do enviado das alturas; seus traços ficavam luminosos e, seu caminhar, cheio de majestade. Um dia, em Paris, quando o canhão disparou pelos acontecimentos da revolução, ele persuadiu-se que era para lhe render homenagem; exigiu silêncio à sua volta e não pôde mais conter a alegria. Talvez esta seja a imagem mais verdadeira da inspiração sobrenatural, ou, antes, da ilusão fantástica dos antigos profetas.

\section{(p. 54 a 66)}

\section{V - História de uma mania em que o tratamento moral teria sido necessário}

Um jovem homem de 24 anos e dotado de uma ardente imaginação, vem a Paris para continuar seus estudos, e acredita que é destinado pela natureza a desempenhar mais tarde o mais brilhante papel no tribunal. Aplicação contínua, vida passada em retiro, sobriedade extrema para dar mais impulso às suas faculdades morais, regime pitagórico, adotado com todo o rigor do termo. Alguns meses depois, dores de cabeça violentas, sangramentos freqüentes do nariz, apertos espasmódicos do peito, dores vagas dos intestinos, flatulências incômodas, sensibilidade moral muito exaltada. Algumas vezes ele me aborda com 
um ar radiante de alegria, e não pode exprimir a felicidade suprema que diz experimentar em si mesmo; outras vezes eu o encontro mergulhado nos horrores da consternação e do desespero, e ele me faz as mais vivas solicitações para colocar fim a seus sofrimentos; as mais profundas características da hipocondria eram fáceis de serem reconhecidas. Eu descrevo para ele os perigos conseqüentes e muitas vezes lhe exorto a mudar sua maneira de viver; mas ele sempre prossegue seu plano com a mais inflexível obstinação; alternativas mais freqüentes de um extremo abatimento e de uma alegria convulsiva, terrores pusilânimes, sobretudo nas sombras da noite, angústias inexprimíveis. Algumas vezes ele vinha me encontrar derretido em lágrimas, e me suplicando para arrancá-lo dos braços da morte; eu o arrastava então pelos campos e algumas voltas de passeio com propósitos consoladores pareciam devolver-lhe uma nova vida; mas em seu retorno para o quarto, novas perplexidades, terrores pusilânimes renascentes, ele sente um aumento de desolação e de desespero na confusão crescente de suas idéias, a impossibilidade de dedicar-se ao estudo, de agora em diante, e a convicção atormentadora de ver dissipar-se a perspectiva de celebridade e de glória para o futuro, a qual sua imaginação havia acalentado; a mais completa alienação segue de perto. Um dia encena-se a peça Filósofo sem o saber, ele entrega-se ao espetáculo para distrair-se, e desde então ei-lo assaltado pelas mais negras e mais sombrias desconfianças; torna-se firmemente persuadido que foram encenados seus ridículos: ele me acusa de haver eu mesmo fornecido os materiais da peça, e desde a manhã seguinte ele vem me fazer as mais sérias e as mais amargas recriminações, de haver traído os direitos da amizade e de havê-lo exposto ao desprezo público. Seu delírio não tem mais limites; ele acredita ver, nos passeios públicos, comediantes travestidos de monges e sacerdotes para estudar todos os seus gestos e surpreender o segredo de seus pensamentos. Na sombra da noite, acredita ser atacado ora por espiões, ora por ladrões e assassinos; e uma vez ele propaga um alarme pelo bairro, abrindo bruscamente as janelas e gritando com todas as suas forças que queriam matá-lo. Um de seus pais determina-se a fazê-lo submeter-se ao tratamento da mania no hospital central logo em frente. E vinte dias depois, o faz partir com um companheiro de viagem para ficar numa pequena cidade vizinha dos Pirineus. Porém, com a moral e o físico igualmente enfraquecidos, sempre entre as alternativas de alguns desvios no mais extravagante dos delírios ou dos acessos de sua negra e profunda melancolia, ele condena-se a um isolamento profundo na casa de seus pais: tédio, desgosto insuperável pela vida, recusa de qualquer comida, grosseria contra tudo que o cerca; finalmente, ele engana a vigilância que o cuida, foge de camisa para um bosque vizinho, perde-se, chega ao fim por fraqueza e inanição, e dois dias depois é encontrado morto, segurando em sua mão o famoso livro de Platão sobre a imortalidade da alma. 


\section{VI - Vantagens da arte de dirigir os alienados para ajudar o efeito dos medicamentos}

Que vantagem seria ter podido entregar à sociedade um homem jovem dotado, antes de seus desvios das mais estimáveis qualidades, e cujos princípios exagerados de conduta aceleraram a perda!

No tratamento de sua mania, eu tinha o poder de usar um grande número de remédios, mas o mais poderoso de todos faltou-me: aquele que só se pode encontrar num hospício bem organizado, aquele que consiste, por assim dizer, em subjugar e domar o alienado colocando-o na estreita dependência de um homem que, por suas qualidades físicas e morais, seja apto a exercer sobre ele um domínio irresistível e a mudar a cadeia viciosa de suas idéias.

Alguns exemplos escolhidos, e que se passaram no hospício de alienados de Bicêtre, tornarão mais clara essa verdade.

\section{VII - Efeitos úteis de uma repressão enérgica}

Um militar, ainda num estado de alienação, depois de ter se submetido ao tratamento comum do hospital central, é repentinamente dominado pela idéia exclusiva de sua partida para o exército. Depois de se ter tentado em vão todas as vias da doçura, recorreu-se à força para fazê-lo entrar à noite em seu alojamento; ele reduz tudo em pedaços durante a noite, e está tão furioso que foi preciso recorrer às mais fortes amarras. Ele é deixado assim, manifestar nos dias seguintes, seu arrebatamento impetuoso; sempre irritações extremas, sempre os acessos de fúria; é apenas por meio de insultos que ele responde ao chefe, cuja autoridade finge desconhecer. Oito dias passam-se nesse estado violento e enfim, ele parece pressentir que não tem o poder para seguir seus caprichos. Pela manhã, durante a ronda do chefe, ele assume o mais submisso dos tons, e, beijando-lhe a mão: "você me prometeu, ele lhe diz, de me dar liberdade dentro do hospício, se eu estivesse tranqüilo; e, bem! Eu lhe intimo a manter sua palavra”. O outro manifesta-lhe, sorrindo, o prazer que sente por esse feliz retorno a si mesmo; ele lhe fala com doçura e no mesmo instante faz cessar todo constrangimento que teria sido supérfluo ou mesmo prejudicial, de agora em diante; sete meses de permanência no hospício foram suficientes para fortalecer a razão desse militar, e ele foi devolvido à sua família e à defesa da pátria, sem ter experimentado uma recaída desde então. 


\section{VIII - Vantagem de abalar fortemente a imaginação de um} alienado em certos casos

Um homem jovem, consternado pela queda do culto católico na França, e dominado por preconceitos religiosos, tornou-se maníaco e depois do tratamento usado no hospital central, é transferido para Bicêtre. Nada iguala sua sombria misantropia; ele nada fala senão dos tormentos da outra vida e pensa que para deles escapar, deve imitar as abstinências e as mortificações dos antigos anacoretas. Desde então, ele se proíbe qualquer comida e por volta do quarto dia dessa resolução inabalável, seu estado de langor faz temer por sua vida; sermões amigáveis, convites insistentes, tudo é em vão; ele repele com dureza uma sopa que lhe é servida, e aplica-se em separar a palha de seu colchão para deitar-se sobre as tábuas. O curso de suas idéias sinistras poderia ser destruído ou contrabalançado de outra maneira, a não ser pela impressão de um temor vivo e profundo?

É nessa perspectiva que o cidadão Pussin apresenta-se à noite na porta de seu alojamento, com uma aparência própria para assustar, o olho em fogo, um tom de voz fulminante, um grupo de pessoas de serviço comprimidas em volta e armadas de correntes fortes que agitam em tumulto; uma vasilha de sopa é colocada junto do alienado e ele é intimado com a ordem mais estrita para tomála durante a noite, se não quiser incorrer nos mais cruéis tratamentos. Retiramse e o deixam no mais penoso estado de flutuação, entre a idéia da punição que o ameaça, e a perspectiva assustadora dos tormentos da outra vida. Após uma luta interior de várias horas, a primeira idéia o arrebata e ele determina-se a tomar seu alimento. Em seguida, é submetido a um regime próprio para restabelecê-lo; o sono e as forças voltam gradativamente, assim como o uso de sua razão, e ele dessa maneira escapa de uma morte certa. Foi durante sua convalescença que ele muitas vezes fez a mim a confissão das agitações cruéis e das perplexidades durante a noite de sua provação.

\section{IX - Intimidar o alienado, mas em absoluto permitir-se qualquer ato de violência}

Os exemplos precedentes referem-se ao caráter e aos felizes efeitos de uma espécie de aparelho de temor, de uma oposição firme e invariável às idéias dominantes e à obstinação inflexível de certos alienados, de uma determinação corajosa e imponente, mas que exclui qualquer ultraje, isenta de todo sentimento de aspereza ou de cólera, e conforme os direitos sagrados da humanidade. Basta indicar a extrema diferença que existe da dureza grosseira, dos golpes, dos ferimentos, ouso dizer, dos tratamentos atrozes e algumas vezes mortíferos que 
se podem cometer nos hospícios de alienados, onde as pessoas em serviço não são contidas pela mais ativa e mais severa vigilância.

Por que encontramos nos escritos dos antigos, e principalmente nos de Celso, uma espécie de método intermediário, um sistema de meios curativos baseados nas punições severas pela fome, pelos golpes, pelas correntes, para reprimir o alienado, quando os avisos e os meios através da doçura tornam-se inúteis? Por que estabelecimentos públicos ou particulares têm sido dirigidos por princípios análogos? Um fazendeiro do norte da Escócia, que tinha uma estatura de Hércules, tornou-se famoso pela cura da mania, sob os cuidados do Dr. Grégory. Seu método consistia em submeter os alienados aos mais penosos trabalhos da cultura, em variar suas funções, em empregá-los; alguns a título de animais de carga, outros como domésticos; a reduzi-los, enfim, à obediência por meio de espancamentos ao menor ato de revolta.

Usando princípios análogos, dirigiu-se uma espécie de estabelecimento monástico muito renomado, numa das partes meridionais da França. Um dos encarregados fazia todos os dias a ronda nos alojamentos, e quando um alienado extrapolava, fazia algazarra, recusava deitar-se à noite, recusava qualquer comida etc., ele o intimava com uma ordem direta para mudar e o prevenia que a obstinação em seus desvios seria punida no dia seguinte com dez golpes com nervo de boi. A execução da sentença era sempre pontual, e se fosse necessário, era inclusive renovada por várias vezes. Não se era menos exato em recompensar do que em punir; e se o alienado mostrava-se submisso e dócil, era levado a tomar suas refeições no refeitório, ao lado do diretor, como se fosse para colocálo à prova. E se à mesa ele se esquecesse e cometesse a menor falta? Era advertido no mesmo instante por um golpe de vareta, batida duramente em seus dedos e, depois, acrescentava-se com uma gravidade calma que ele havia errado e que deveria observar-se com maior prudência. Deve-se lamentar que o doutor Willis ainda não tenha chegado a conciliar o tratamento da mania com os princípios rígidos da mais pura filantropia, já que no estabelecimento que ele formou nos arredores de Londres, cada alienado tem um guardião que pode dar golpes sem motivo, o que dá à brutalidade deste último uma latitude indeterminada e perigosa.

\section{X - Máximas de doçura e de filantropia a serem adotadas nos hospícios}

Seria talvez cair na imprecisão, tratar de forma geral e uniforme para todos os povos, a questão da instituição moral dos alienados por pancadas e castigos corporais; pois como assegurar que os negros que vivem em servidão na Jamaica, ou os escravos russos, adaptados a um sistema opressor durante a vida toda, 
não devam ser submissos, no caso de alienação, às mesmas leis de um jugo duro e despótico?

Mas alguns efeitos favoráveis poderiam em geral ser esperados do temor aplicado à cura da mania. A sensibilidade viva do francês e sua reação violenta contra todo revoltante abuso do poder, enquanto ele conservar um clarão de razão, não devem determinar em favor das formas de repressão mais doces e mais de acordo com seu caráter? Aliás, todos os fatos observados não vêm em apoio desses princípios? Quantos movimentos ardentes, ou melhor, quantos acessos de raiva e de indignação, eu não vi estourar entre certos alienados quando pessoas de mau gosto que vinham visitar o hospício faziam brincadeiras desumanas ao importuná-los ou ao provocá-los? Na própria enfermaria de alienados, que era isolada do hospício e fora da vigilância do chefe comum, quantas vezes não aconteceu por causa de zombarias bobas de enfermeiros ou de grosserias brutais, que alienados calmos e em vias de suas curas, recaíssem em acessos de furor por contrariedades deslocadas ou atos de violência? E, ao contrário, alienados transferidos para o hospício e tidos ao chegarem como muito coléricos e muito perigosos, por terem sido muito exasperados fora dali por pancadas e maus tratamentos, parecem de repente assumir um temperamento oposto, porque lhe falam com doçura, compadecem-se de seus sofrimentos e lhe dão a esperança consoladora de uma sorte mais feliz. Em seguida, a convalescença faz progressos rápidos, sem nenhum outro artifício. Enfim, a mais constante experiência não ensina que, para tornar duráveis e sólidos os efeitos do temor, esse sentimento deve aliar-se com o da estima na medida em que a razão retoma seus direitos? O que supõe que a repressão, que não deixou de trazer a característica da irritação ou de um rigor arbitrário, só foi usada para vencer a petulância indócil do alienado tal como uma força proporcional ao grau de resistência, e que se foi levado apenas pelo desejo sincero de reconduzi-lo a si mesmo, como o prova imediatamente depois seu arrependimento, uma explicação franca e amigável.

Aqui estão os princípios que se segue estritamente no hospício de alienados de Bicêtre. Estamos, sem dúvida, muito longe de ter as vantagens do sítio, da posição do local, de sua extensão, de sua distribuição anterior, tal como as possui o Doutor Fowlen em seu estabelecimento na Escócia. Mas posso atestar, a partir de uma observação assídua de dois anos consecutivos, que as mesmas máximas da mais pura filantropia presidem a direção dos alienados de Bicêtre; que o pessoal de serviço não levanta a mão violenta sobre eles, sob qualquer pretexto que seja, mesmo por represálias; que as camisas de força e a reclusão por um tempo muito limitado são as únicas penas infligidas; e que na falta de sucesso pela via da doçura ou de um aparelho que impõe repressão, um estratagema hábil algumas vezes produz curas inesperadas. 